\title{
Outlook of future discharge at the dam watershed considering climate change
}

\author{
D. K. Koh \& J.-H. Park \\ Water Resources Research Center, K-water Institute, \\ Daejeon, Republic of Korea
}

\begin{abstract}
Rapid climate change has made the job of water managers harder and has increased the imperative for considering climate change impacts on rainfall and runoff predictions. The purpose of this study is to predict future runoffs at the Yongdam and Daechung dams under meteorological regimes adjusted for the impacts of climate change. For this study, weather series data including temperature and precipitation forecasts up to the year 2090 were used. These forecasts are compiled and disseminated officially by the Korea Meteorology Agency (KMA). The forecasts are generated using mesocale (MM5) Regional Circulation Model (RCM) (27 km resolution) and Intergovernmental Panel on Climate Change's (IPCC) A1B emissions scenario, employing the results of coupled climate model ECHO-G (400 km resolution) as boundary conditions. SWAT (Soil and Water Assessment Tool) was used for rainfall-runoff modeling for the period 2011 to 2010 . The GIS based SWAT model can simulate temporal and spatial distributions of surface and subsurface flows. The weather series was fed into the SWAT model to simulate the streamflows associated with other hydrologic components such as subsurface flow, soil moisture contents etc. This approach is applied to the Yongdam Dam and Daechung Dam in the Geum River Basin, Korea. The results show that annual mean inflow to the dam reservoirs will be decreased by $7.6 \%$ compared to the latest 10 year observation. Regarding the seasonal variation, dam reservoir inflows during winter and autumn are going to increase, while in summer less inflow is predicted. It is necessary to conceive a strategy for dam development and management, which is cognizant of the impacts of climate change.
\end{abstract}

Keywords: climate change, discharge, RCM, SWAT, A1B scenario. 


\section{Introduction}

The frequency of water-related disasters such as drought and flood has been increasing all over the world through the last few decades. Intergovernmental Panel on Climate Change (IPCC) report states that the impacts of climate change in the water sector are already being observed, and predicts that the effects of climate change would only significantly increase in the future.

Because of recent climatic change due to global warming, the management of water resources in Korea is gradually becoming more difficult. While the global mean temperature has risen by $0.74^{\circ} \mathrm{C}$ since the late 19 th century, in Korean peninsular the increase has been more than double the global average at $1.7^{\circ} \mathrm{C}$. According to a report of KMA (Korea Meteorology Agency) Institute, a further increase of $5^{\circ} \mathrm{C}$ in temperature and $17 \%$ in precipitation is expected by the year 2100 in Korea.

It is also anticipated that the frequency of localized rainfall events of more than $100 \mathrm{~mm} /$ day will increase 2.7 times, and extreme rainfall events of more than $1,000 \mathrm{~mm} /$ day, super typhoon, or two huge typhoons may occur simultaneously in the future due to the climate change. So far, the highest daily maximum rainfall was $870 \mathrm{~mm}$ in 2002 by typhoon RUSA at Gangreung city in central-eastern coastal area of Korean Peninsular, which caused upwards of US\$ 5 billion in property loss and 246 casualties.

The chance of drought occurrence is expected to increase 3.4 times and the stream discharge decrease $5.7 \%$ during drought season due to rise in mean temperatures and as a consequence of increased evapotranspiration.

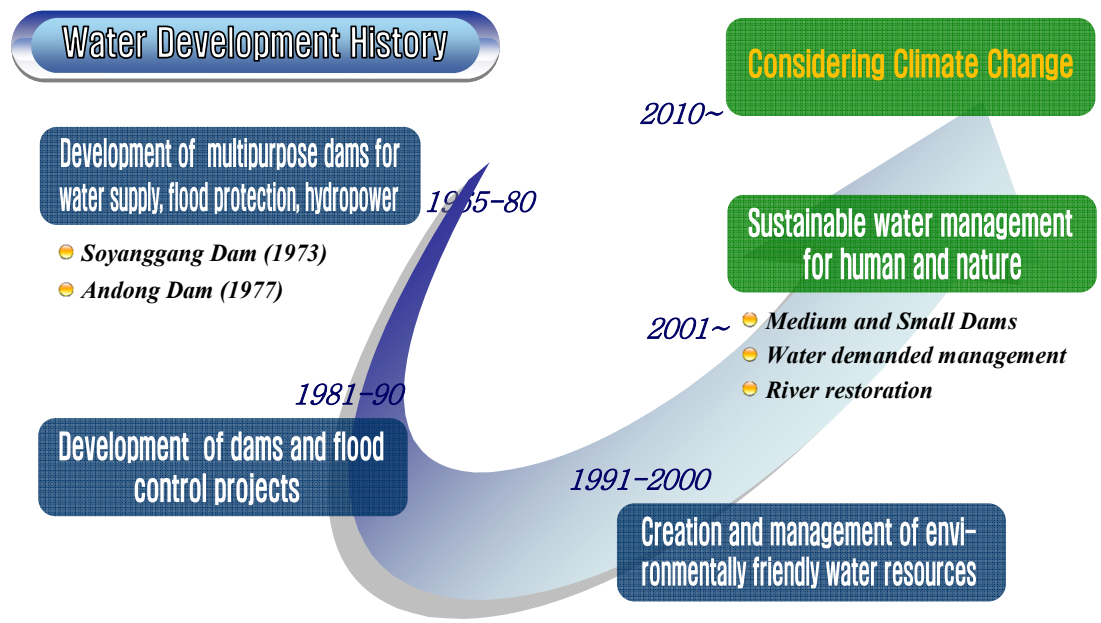

Figure 1: The history of water development in K-water.

Managing climate change impacts is the most important future challenge facing K-water, which has been implementing national water resources management policies by construction and management of large multipurpose 
dams in Korea since its establishment in 1967. A definite action plan is required to adapt to climate change through vulnerability assessment, policy change, and institutional and legal improvements. K-water has just launched a new strategic research project to model and forecast the climate change impacts on water resources management, especially on dams and devise proper action plans to adapt to climate change.

In this paper, we are trying to predict runoff at Yongdam and Daechung dams under the impact of climate change, for better future planning. ECHO-G model data has been provided by KMA as the optimum Global Circulation Model (GCM) data for the Korean peninsula. MM5 model based on A1B scenario with 27 kilometers of space resolution that exploits dynamic downscaling technique is used for producing future rainfall data on a regional scale. The weather series so obtained is fed into a semi-distributed hydrological model called SWAT to simulate the runoffs. This approach is applied to the Yongdam Dam and Daechung Dam Basin in the southern part of Korea.

\section{Study area}

Geum River is located in central part of the Korean peninsula. The river is $401 \mathrm{~km}$ long, making it the third longest in South Korea. The basin area is $9,805 \mathrm{~km}^{2}$ equivalents to $10 \%$ of this country. There are several big cities in the river basin including Daejeon, Cheongju and Jeonju. The Daechung Dam is located at $150 \mathrm{~km}$ upstream from the estuary of the Geum River, which flows into the Yellow Sea.

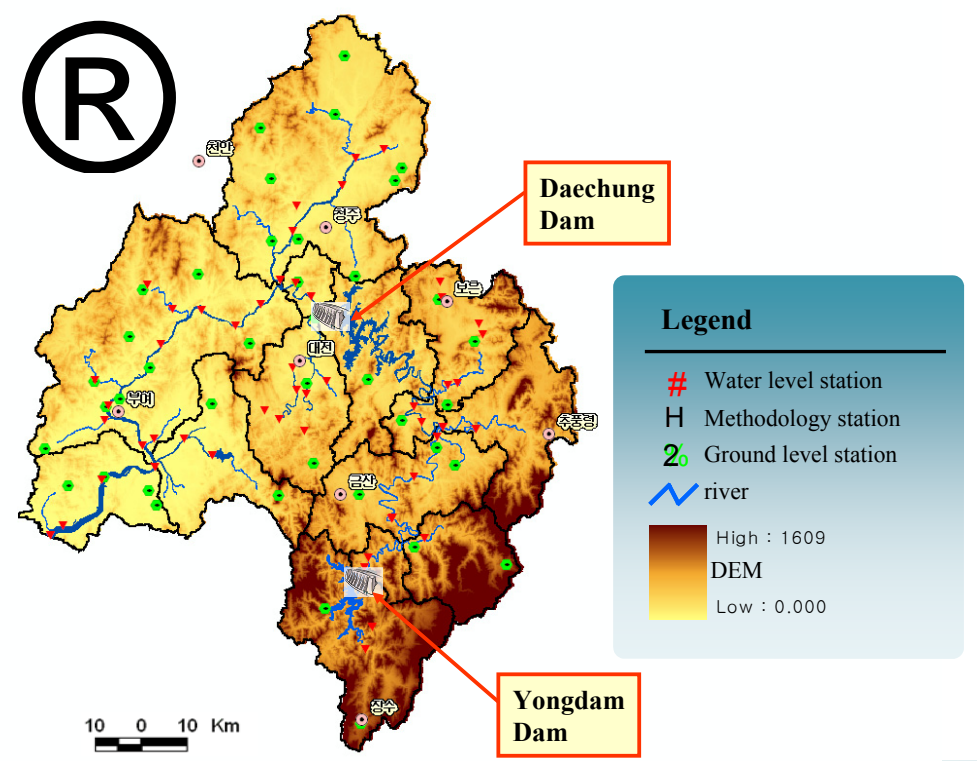

Figure 2: $\quad$ Location of Daechung Dam (up) and Yongdam Dam (down). 
Principal facilities of the dam include a main dam and reservoir, a reregulation dam, three saddle dams, a hydropower plant, and two water supply systems to the Daejeon and Cheongju areas. Yongdam Dam is located at JinanGun, Cheonbuk Province, which is generally recognized as area of low water contamination. Yongdam Dam diverts the water of the Geum River, where relatively abundant water flows, into the Mankyung River Basin Area, which lacks municipal and industrial flow inputs. There are Jeonju City, Nonsan City and Gunsan City, etc. in the Mankyung River Basin. Total capacity of the reservoir is 815 million $\mathrm{m}^{3}$, and part of this reservoir's water flows through a diversion tunnel whose length and diameter are $21.9 \mathrm{~km}$ and $3.2 \mathrm{~m}$, respectively. This dam is to supply about 500 million $\mathrm{m}^{3}$ of water per year solving the water deficit problem until 2023. A hydropower plant is constructed at the outlet side of the diversion tunnel to utilize the high head difference.

\section{Climate change adjustment for meteorological data}

\subsection{Statistical analysis of hydrologic time series data}

Efforts to quantitatively assess the influence of climate change have included statistical analyses such as analyses of limiting values, trend analysis based on Mann-Kendall test, correlations among the elements, and variance of the 10-year moving average. The results are available from KMA and K-Water as time series data of the weather and hydrology of Geum River for the last thirty years. As shown in Fig. 3, temperature and rainfall has been increasing during last 30 years for the Geum River basin. Annual average temperature has increased by $0.6^{\circ} \mathrm{C}$ during last 30 years, especially winter temperature has increased by $1.1^{\circ} \mathrm{C}$. Annual rainfall has increased by $152.9 \mathrm{~mm}$ compared with 30 years ago. This means that variation of temperature and rainfall due to climate change will directly affect water resources. Temperature is anticipated to further increase by $5^{\circ} \mathrm{C}$ and precipitation $17 \%$ over the next 100 years in Korea. According to the outlook of climate change in water resources of Korea, localized rainfall
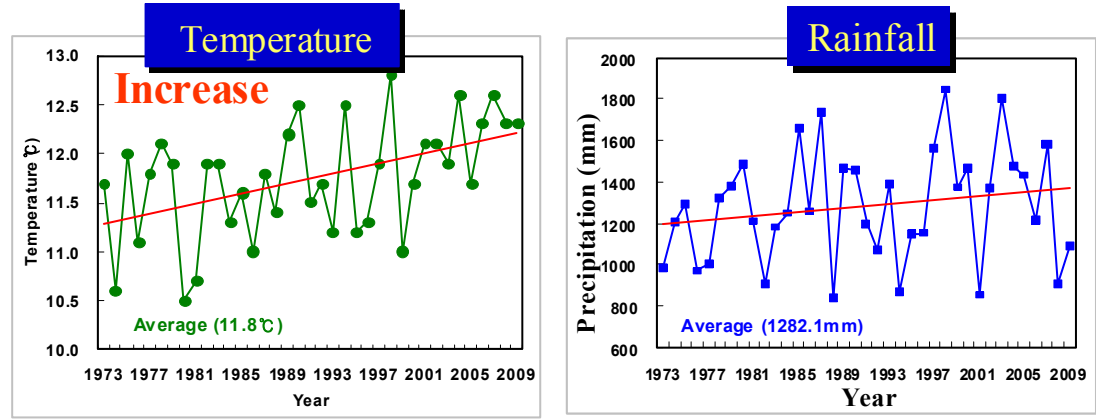

Figure 3: Analysis results for time series trend of temperature and rainfall. 
frequency over $100 \mathrm{~mm} /$ day is anticipated to increase 2.7 times and extreme event over $1,000 \mathrm{~mm} /$ day and super typhoon over $70 \mathrm{~m} / \mathrm{sec}$ may occur more frequently because of rise in sea-surface temperatures.

\subsection{Downscaling of climate data}

ECHO-G model has the resolution of $400 \mathrm{~km}$ as an optimized GCM model on the Korean peninsula. MM5 model based on A1B scenario with 27 kilometers of space resolution that exploits dynamic downscaling technique was used for producing future rainfall data at a regional scale.

Since GCM and Regional Circulation Model (RCM) cannot be directly utilized in conjunction with each other because of the differences in their respective temporal and spatial scales, the RCM grid data have been downscaled spatially from basins to points for rainfall-stations. Similarly, the seasonal precipitation scenarios due to climate change impacts have been downscaled to daily precipitation series. The A1B scenario has been used as basic input data for multi-point irregular downscaling methods, and the time series of daily precipitation reflecting influences of climate changes have been analyzed for major points along the Geum River.


Figure 4: $\quad$ Downscaling process based on A1B scenario.

Also, variability in the precipitation events with regard to the future climate changes have been examined using diverse methodologies to account for irregularities overlooked during the existing daily precipitation simulation and multi-point irregular downscaling, in order to produce detailed hydrology scenarios for each sub-watershed. Analysis periods including the reference period from 1970 to 2000 are as follows; 2015s (2001-2030), 2045s (2031-2060), and 2075s (2061-2090). 


\section{Model setup}

SWAT - a semi distributed runoff model- has been selected for rainfall-runoff modeling after careful review of six models in terms of existing model awareness amongst researchers, research outputs, and suitability for researchers.

SWAT is a river basin or watershed, scale model developed by Dr Jeff Arnold for the USDA Agricultural Research Service (ARS). SWAT was developed to predict the impact of land management practices on water, sediment and agricultural and chemical yields in large complex watersheds with varying soils, land use and management conditions over long periods.



Figure 5: $\quad$ Structure of SWAT model.

The GIS based SWAT model can simulate temporal and spatial distribution of surface flows and sub-surface flows per small basins, and accepts input parameters in the form of DEMs, land use and soil type maps.

\subsection{Calibration}

Using the SWAT model for calibration period 2001 to 2006, the comparison of simulated and observed discharge at Yongdam Dam in the Yongdam basin reveals $90.1 \%$ accuracy. Similarly, the simulated discharge at Cheonchun flow station matches the observed flow with $91.3 \%$ accuracy. Therefore, model has reasonable accuracy for applicability to watersheds feeding to Yongdam and Daechung dams for the purposes of this study. The data for calibration exercise is shown in Figures 6, 7 and 8. 

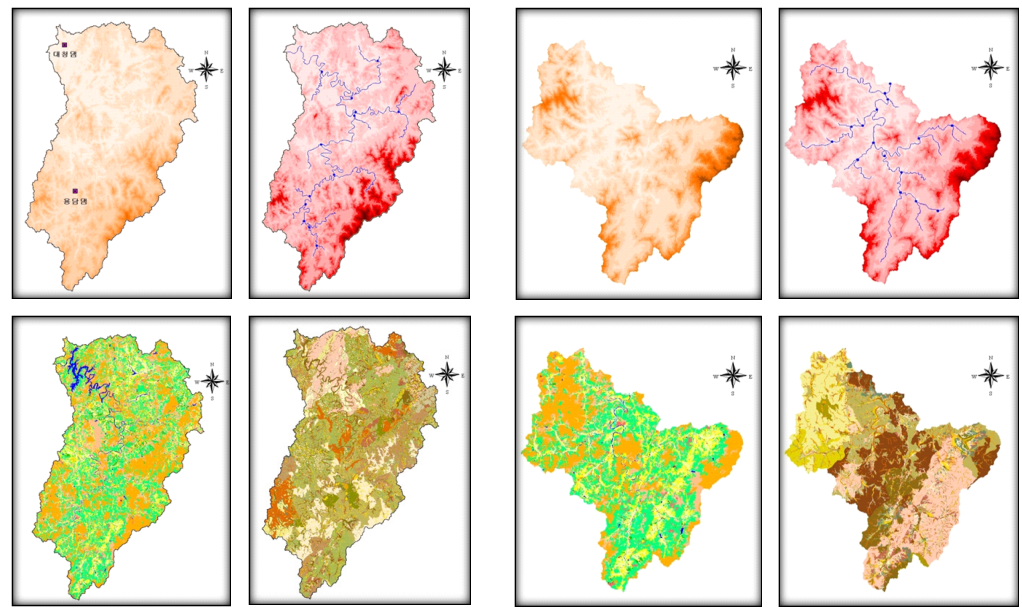

Figure 6: GIS data of Daechung Dam (left) and Yongdam Dam (right) Watersheds.

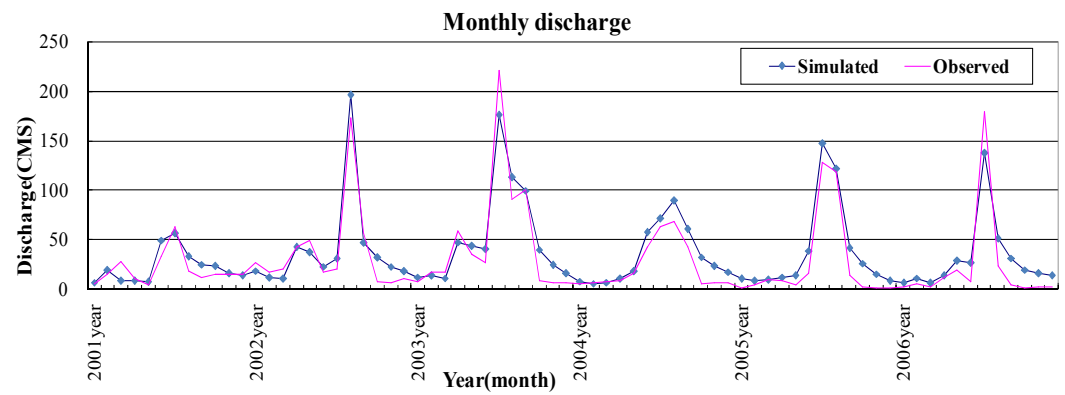

Figure 7: Comparison between simulated and observed hydrographs (Yongdam).

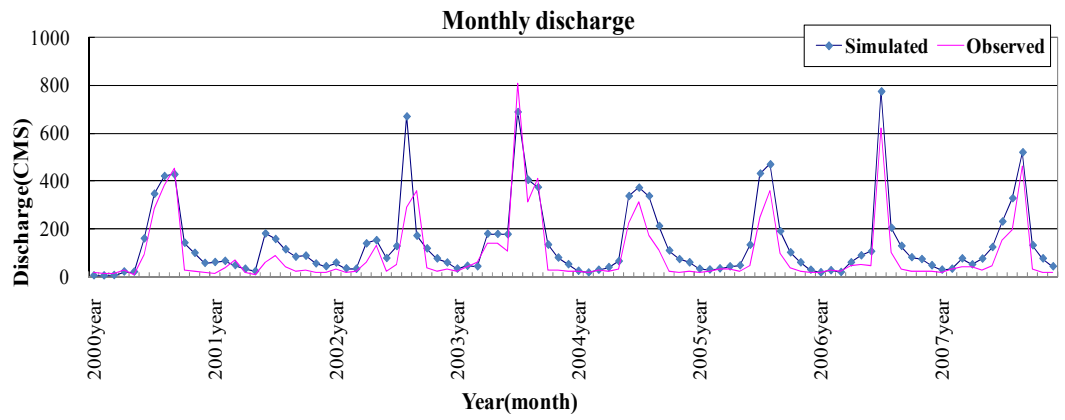

Figure 8: Comparison between simulated and observed hydrographs (Daechung). 


\section{Simulation and results}

The simulation period was set at 80 years; from 2011 to 2090 . The outcome of the analyses predicts that the amount of run-off will increase by $18 \%$ between 2011 and 2020. The results show that annual mean streamflow will be reduced by $7.6 \%$ under $\mathrm{A} 1 \mathrm{~B}$ scenario over the simulation period and while seasonal streamflows in the winter and autumn will increase, streamflow in the summer seasons will be decreased. However, the seasonal variation of the simulated series is similar to the observed pattern.
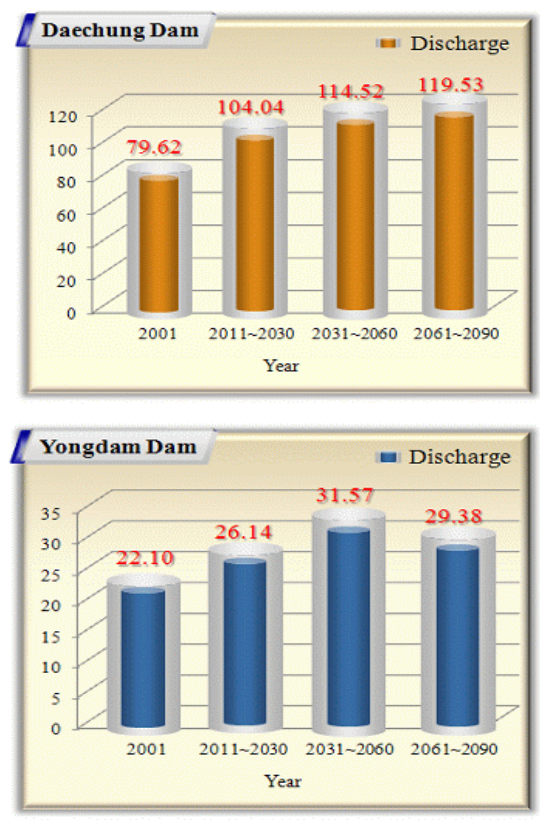

Figure 9: $\quad$ Simulation results of discharge for next 90 years.

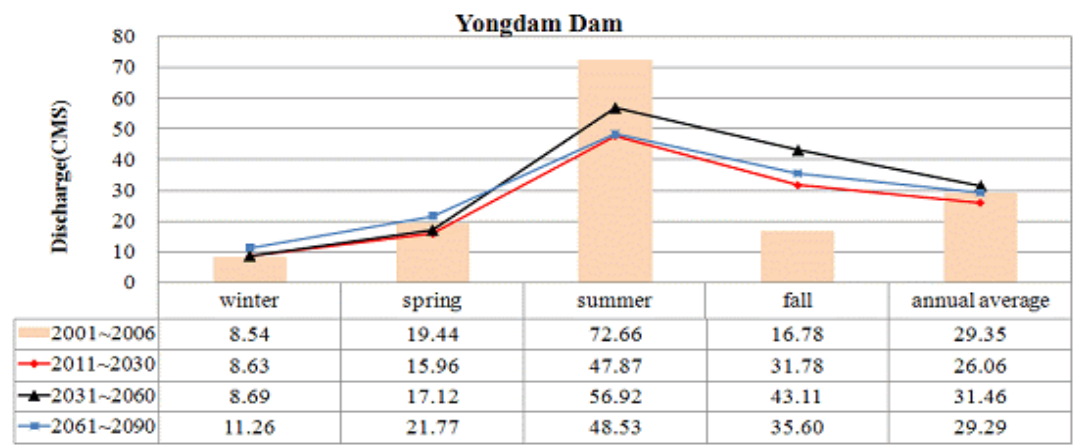

Figure 10: Seasonal outlook of future discharge (Yongdam Dam). 


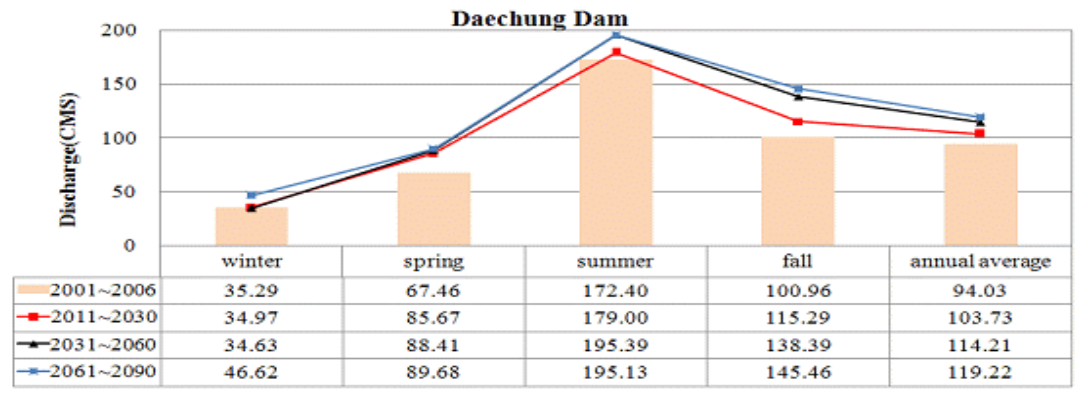

Figure 11: Seasonal outlook of future discharge (Daechung Dam).

Using the results of this research, the dam management pattern can be changed from seasonal management to satisfy water demand during dry periods to an annual water storage system to distribute water by necessity in the future.

\section{Conclusions}

In this paper, we are trying to propose a future plan for dam management through quantitative evaluation of discharge variation at dams under the impacts of climate change.

ECHO-G model data was obtained from KMA as an optimized GCM model for the Korean peninsula. MM5 model based on A1B scenario with 27 kilometres of space resolution that exploits dynamic downscaling technique was used for producing future rainfall data on a regional scale. GIS based SWAT model was used to simulate temporal and spatial distribution of surface flow and sub-surface flow per small basins, and input data in the form of DEMs, land use and soil types were developed for pre-processing. The weather series data was fed into the SWAT model to simulate the discharge at Yongdam Dam and Daechung Dam Basin in southern part of Korea. The results show that annual mean flow is reduced by about $7.6 \%$ over the simulation period of 80 years (2011 to 2090). While Seasonal streamflows during winter and autumn increased, simulated summer streamflow was found to be less compared to observed values. The seasonal variation of the simulated series is similar to the observed pattern.

Additionally, a strategy for future dam watershed management considering climate change were proposed.

\section{Acknowledgements}

This study was backed up by the Technical Innovation of Construction Program (Ecoriver21, 06B01) that is funded by the Ministry of Land, Transport and Maritime Affairs of Korea. 
104 Water and Society

\section{References}

[1] K-water Institute, A study for the generation of corresponding plan on climate change for future water resources management, 2010.

[2] Korean national committee on large dams, http://www.kncold.or.kr/

[3] S.L. Neitsch, J.G. Arnold, J.R. Kiniry, J.R. Williams, Soil and water assessment tool theoretical documentation, 2001. 